L.S. Namazova-Baranova ${ }^{1,2,3}$, T.V. Turti ${ }^{1}$, I.A. Belyaeva ${ }^{1}$, E.P. Zimina ${ }^{1}$, S.B. Lazurenko ${ }^{1}$, M.D. Mitish ${ }^{1}$, E.A. Bakovich ${ }^{1}$, M.S. Rtichsheva ${ }^{1}$, N.Y. Savvateeva ${ }^{1}$

${ }^{1}$ Scientific Center of Children's Health, Moscow, Russian Federation

2 Sechenov First Moscow State Medical University, Russian Federation

${ }^{3}$ Pirogov Russian National Medical Research University, Moscow, Russian Federation

\title{
Modern methods of preserving breast feeding in children of the first months of life with health disorders
}

\section{Author affiliation:}

Turti Tat'yana Vladimirovna, $\mathrm{PhD}$, head of the department of clinical pediatric studies of the Scientific Center of Children's Health (Federal State Budgetary Institution)

Address: 2/3, Lomonosovskii Ave., Moscow, 119991; tel.: +7 (499) 134-07-45; e-mail: turti@nczd.ru

Article received: 22.03 .2014 . Accepted for publication: 14.05.2014.

The issue of preserving and prolonging breast feeding is relevant for many countries around the world. It is especially relevant in premature infants and the children born with various perinatal pathologies. Scientific literature features the primary reasons of weaning: work activity resumption by nursing mothers, milk deficiency, breast refusal, insufficient awareness of mothers. The article presents results of two studies performed at the Scientific Center of Children's Health. Results of a medical-psychological-pedagogical questioning of 85 mothers of premature infants demonstrate insufficient work of medical personnel in the sphere of preserving breast feeding in whole and in the children born with perinatal pathologies in particular; and the need of young women and their families in obtaining information on the benefits of breast feeding, training and assistance in the course of parental performance. The study resulted in formulation of recommendations on breast feeding support. It is important to establish the possibility to return to full breast feeding after enforced weaning and in the event of supplementary/mixed feeding. Results of the second study $(n=33)$ demonstrated that the use of special medical devices (pacifiers, feeding bottles) developed on the basis of thorough research in the sphere of maternal breast sucking physiology in natural feeding termination risk group children helps to preserve children's need therein and ensures efficient return of children to maternal breast feeding.

Keywords: breast feeding, breast milk, neonates, premature infants, weaning reasons, special medical devices (feeding bottles, pacifiers).

Ensuring physiological duration of breast feeding is a relevant issue for many countries around the world. Results of polling 2,266 health professionals, 100 of whom were from Russia, were communicated at the Madrid summit of the Global Breastfeeding Initiative in 2012.

The following specialists were polled: general practitioners -2 out of $2,266(0 \%)$, pediatricians $42 / 12 \%$, obstetrician/gynecologists $-3 / 44$, nutritionists $-7 / 12$, neonatologists $-3.4 / 6$, lactation consultants $-5 / 6$, nurses $-7.5 / 2$, others $-30.1 / 20$. The average duration of professional activity of health professionals was 17 years; of health professionals from Russia - 22 years. $57 \%$ of all the respondents and $85 \%$ of the Russian respondents gave a negative answer to the question "Is insufficient duration of breast feeding a healthcare problem in your country?" The most frequent causes of renunciation of breast feeding (5-point scale score) were as follows: mother's milk deficiency $-3.1 / 3.2$; breast refusal $-1.3 / 1.4$; breast feeding is excessively time-consuming 2.2/1.1; breast feeding became painful - 2.2/0.9; insufficient breast feeding awareness of the mother $-2.9 / 2.4$; work activity resumption by the mother $-3.5 / 2.5$. 
Thus, the most frequent cause of breast feeding termination around the world is work activity resumption by the mother, in the Russian Federation - milk deficiency; insufficient breast feeding preservation awareness is another important aspect.

Breast milk is a unique natural perfectly balanced food substance for all infants. Numerous studies have confirmed the assumptions that breast milk is a natural tissue, which is almost $100 \%$ identical to the neonate's tissues. That is the basis of work on successful breast feeding support $[1,2]$.

Advantages of breast feeding are as follows:

- optimal composition of breast milk satisfies the child's food demands to the highest extent possible;

- high assimilability of proteins, fats, carbohydrates and mineral substances;

- presence of enzymes, hormones, biologically active agents and immune factors (cells) responsible for anti-infectious, antiviral and antibacterial protection of the child's body in breast milk;

- psychological and physiological contact of the mother and the child;

- physiological colonization of the neonate's intestinal microflora;

- economical-temporal aspect: breast milk is absolutely free and takes no time for preparation.

Establishment of a close emotionally positive mutual bond between the neonate and the mother in the course of feeding is an important argument in favor of breast feeding. This bond in particular and the process of breast feeding in whole are among the factors determining further child's health and socialization.

In mothers of premature infants, the breast milk has a specific composition fit to satisfy increased needs of such children in nutrients to the highest degree possible and adequate to their physiological maturity. Such milk is characterized by high caloric content: the concentration of proteins and fats therein is higher, especially in colostrum and transitional milk, whereas the lactose concentration is lower than in the milk of mothers of term infants (the amount of total carbohydrates is the same) [3, 4].

Numerous studies have confirmed the following statements regarding breast feeding of premature infants:

- considerable decrease in morbidity [5-7];

- decrease in the risk of necrotic enterocolitis [5, 8];

- improvement of food tolerance $[9,10]$;

- decrease in late sepsis [5, 7];

- reduction in inpatient hospital stay duration [7];

- improvement of neurological outcomes [11-15].

Breast-fed premature infants feature better intellectual development than the children fed with milk formulas. Dose-dependent effect of breast milk was observed: thus, every $10 \mathrm{ml}$ of breast milk consumed per $1 \mathrm{~kg}$ of body weight per day added 0.53 points to the index of neuropsychic development of premature infants (Bayley scale) by the postconceptional age of 18-22 months [15].

The data confirming positive impact of breast milk on plastic processes in premature infants have lately been obtained [16]. It has been proved that breast-fed premature infants have a more optimal body composition (smaller fat ratio in tissues) in comparison with the children, who had been consuming specialized milk formulas; this confirms a hypothesis of preventive effect of breast feeding for prevention of late metabolic disorders (hypertonia, cardiovascular diseases, obesity, type 2 pancreatic diabetes).

Breast latching and feeding the premature infant with expressed breast milk have an important psychological aspect: potential for communication (kangaroo care) amplifies the mother's attachment to the child, contributes to development of a bond between them and convinces the mother that she is involved in care of a child.

The aforementioned facts confirm that ensuring breast feeding in premature infants, especially in the child born with very low or extremely low body weight, is a relevant issue of healthcare [17]. 
Breast feeding preservation is also important for the children born with health deviations due to chronic (intrauterine) hypoxia and/or acute (intranatal) asphyxia. Despite the fact that these children exhibit the worst need in breast milk, they are often deprived of it for the reasons associated with these infants' severe postnatal condition.

One of the serious factors of breast feeding termination in the first days of life is the decision made by the medical personnel at the obstetric establishments (nursing stage 2) on supplementary feeding of the ill child with milk formula or total shift of such a child to artificial feeding.

There are only two substantiated weaning causes:

- serious disease and specific infections in the mother: tuberculosis, syphilis, sexually-transmitted infections, other infectious diseases, pancreatic diabetes, suppurative mastitis etc.;

- infeasibility of withdrawing life-saving baseline therapy undergone by the mother, when it produces toxic effect against the neonate at breast feeding (at oncological, autoimmune, rheumatic, psychiatric and other conditions).

All the other causes are only a reason to join in a campaign for breast feeding.

According to the data obtained at the premature infant unit of the Scientific Center of Children's Health (Federal State Budgetary Establishment), which functions in compliance with the "mother and child" principle and provides round-the-clock rooming-in of the mother and the child, the share of exclusive breast feeding of the neonates $(n=198)$ was 32.3 , of mixed feeding $-56.6 \%$, of artificial feeding $-11.1 \%$.

The primary causes of temporary weaning were as follows: child's condition severity, unreadiness for unassisted sucking (tube feeding), supplementary feeding with a formula in the event of the mother's lactation deficiency, lactostasis and nipple pathology.

As insufficient awareness of mothers/families on the possibility to preserve and the need in breast feeding for the children born with perinatal pathologies, including premature infants, often leads to unsubstantiated shift of the children to artificial feeding, special psychology and remedial teaching unit workers analyzed attitude of the mothers of premature infants towards to the process of breast feeding. The analysis was aimed at establishing the conditions necessary for forming lactation dominant in the mothers $(n=85)$.

Birth of a premature or ill child may be considered a reality situation negatively affecting psychological condition of all family members and the whole system of their social relations. Mothers usually suffer from the worst emotional stress. They suffer from severe stress and shock. Mothers of premature infants may suffer from emotional stress for several weeks and even months (depending on their personality traits). The situation is aggravated by the fact of serious hormonal reorganization - pregnancy and labor - that the woman's body has only just endured. Serious emotional discomfort destructively affects the woman's function as a mother, decision-making and consistency of actions. High emotional stress may induce estrangement of the mother from the child and unwillingness to care thereof. The process of maternal attachment formation becomes impaired. The doctor must take such aspects into consideration when presenting mothers with medical information on health status and life prognosis of their children. Mother's active involvement into the process of care, upbringing and health recovery of an infant must be gradual and well-considered. Parents ought to be provided information on the issues of nutrition, treatment, upbringing and development of mental capacities of an ill child from the first days of their rooming-in with their children at the inpatient hospital. Specialists ought to remember that emotionally stressed and physically deteriorated women (especially young primiparas) need special information and mental support, education and assistance with performance of their parental functions. Lack of psychologically comfortable and emotionally warm atmosphere at the inpatient hospital, strained relations with the doctor in charge and prescriptive manner of doctoral talking with the patients may serve as factors negatively affecting the woman's emotional condition, her attitude towards the neonate and processes of lactation and breast feeding. These assumptions have been confirmed by results of this study, as 
it identified the following possible causes negatively affecting the mother's attitude towards breast feeding:

- peculiarities of social and family situation (lack of family support, need in work activity resumption, personal pernicious habits and needs incompatible with breast feeding [smoking, diet, contraceptives etc.]);

- low awareness of benefits and possibilities of breast feeding (lack of objective medical information, attractive advertising of milk formulas etc.);

- objective causes of renunciation of breast feeding (prohibited breast feeding for medical reasons [due to the child's or the mother's disease], significantly reduced or no lactation);

- physical discomfort (disagreeable and painful sensations caused by feeding, difficulty expressing milk).

The factors positively affecting the process of lactation dominant formation were identified as well:

- medical personnel support (confidence in the doctor's recommendations, practical recommendations on the organization of breast feeding);

- support of the closest family and friends and previous experience of breast feeding;

- pleasant emotional sensations in the process of breast feeding, which contribute to formation of attachment in the mother-child diad;

- physiological inclination of the mother to breast feeding.

Therefore, instruction of parents (mothers) on the issues of breast feeding and psychological support of young mothers are important and essential components of breast feeding support, especially for the children born with pathologies.

The data obtained at the premature infant unit indicated the following primary causes of weaning: severe condition and enforced feeding via a nasogastric tube for the child; inability to provide the sufficient amount of feeding (hypogalactia) and enforced supplementary feeding with artificial formulas for the mother. Another observed cause of temporary weaning was feeding with pasteurized breast milk. Expressed breast milk pasteurization was required in the event of rhesus and blood group conflict between the mother and the child and if the breast milk expressed in advance had to have been stored in a refrigerated room for more than 24 hours. In such cases feeding bottles with pacifiers are used for feeding; this often leads to subsequent breast refusal.

Modern technological capacities, detailed study of lactation and sucking mechanisms helped to develop and design a special pacifier, which reproduces peristaltic component of natural breast sucking - Pigeon Peristaltic Plus (Pigeon, Japan). Use of such a feeding bottle with pacifier allow for the possibility to resume breast feeding of the involuntarily weaned children, thus contributing to long natural feeding.

We performed a surveillance non-comparative prospective study of effectiveness of feeding bottle with pacifier Pigeon Peristaltic Plus for resuming breast feeding of neonates, including premature infants, and temporarily weaned children of the first months of life at the units for premature infants and medical rehabilitation of infants with perinatal pathologies of the Scientific Center of Children's Health (Federal State Budgetary Establishment).

The study involved neonates and infants $(\mathrm{n}=33,13(39.9 \%)$ of whom were born prematurely) aged 1-10 weeks, the parents whereof gave informed written consent. Inclusion criteria were as follows: mild or moderate perinatal pathology, deficient birth weight and/or premature infants capable of unassisted sucking.

At the premature infant unit there were 1 neonate with birth weight under 1,500 g, 4 neonates with birth weight of 1,501-2,000 g, 9 neonates with birth weight of over 2,000 g; 1 neonate (35-36 gestational weeks) had a birth weight of 2,880 g. The mean age of the study subjects was 4 weeks. All the 15 (45.4\%) children were diagnosed with degree 1-2 cerebral ischemia.

All the $18(54.5 \%)$ children from the unit for medical rehabilitation of infants with perinatal pathologies involved in the study were born on term; 17 (51.1\%) children had a birth weight over $3,000 \mathrm{~g}, 1(3 \%)-2,930 \mathrm{~g}$. The mean age was 5 weeks. There were $9(27.3 \%)$ children with mild 
or moderate perinatal affection of the central nervous system, $6(18.1 \%)$ children with prolonged conjugated jaundice, $5(15.1 \%)$ children with intrauterine pneumonia and $5(15.1 \%)$ children with respiratory distress syndrome. $1(3 \%)$ child was diagnosed with bronchopulmonary dysplasia, $6(18.1 \%)$ - with lactase deficiency.

$24(72.7 \%)$ children suffered from perinatal affection of the central nervous system.

Satisfactory sucking reflex was observed in children from both units.

Temporary weaning causes were as follows:

- feeding with expressed breast milk despite sufficient lactation due to difficulty breast latching: inverted, taut nipples, nipple fissures (5 women; $15.2 \%$ );

- supplementary feeding with a formula (up to $30 \%$ of the total nutrition in the event of deficient lactation ( 7 women; $21.2 \%$ );

- lingering conjugated jaundice and feeding with pasteurized expressed breast milk (4 women; $12.1 \%)$

- supplementary feeding with expressed breast milk due to correction of severe lactase deficiency with lactase drugs: the enzyme was introduced in the breast milk expressed in advance (4 women; $12.1 \%$ );

- improved health status and readiness to unassisted sucking (in the event of shift from tube feeding to bottle feeding) with expressed breast milk and subsequent breast latching (13 women; $39.4 \%)$.

The mean duration of use of the tested feeding bottle with pacifier in children was 10-14 days. Separate parameters (those which qualitatively characterize physiological process of sucking [aerophagia, colics] and readiness to suck breast) were analyzed. Analysis was performed in the beginning, in the middle and in the end of the study.

\section{RESULTS}

In the beginning of the study, aerophagia was not present at all in $2(6.06 \%)$ children, occurred extremely rarely (2-3 times per day) in $14(42.42 \%)$ children, rarely - in $11(33.33 \%)$ children, frequently (once per hour) - in $6(18.18 \%)$ children. After 14 days, aerophagia was not present at all in $7(21.21 \%)$ children, occurred extremely rarely in $24(72.73 \%)$ children, rarely - in $1(3.03 \%)$ child, frequently - in $1(3.03 \%)$ child (pic. 1$)$.

Thus, aerophagia was observed in 31 children before the study and remained in 26 children in the end of the study. However, aerophagia occurred extremely rarely in $24(72.7 \%)$ neonates.

In the beginning of the study, colics were not present at all in $1(3.03 \%)$ child, occurred extremely rarely (2-3 times per day) in $9(27.27 \%)$ children, rarely - in $14(42.42 \%)$ children, frequently (once per hour) - in $7(21.21 \%)$ children, very frequently - in $2(6.06 \%)$ children. After 14 days - in $14(42.42 \%), 12(36.36 \%), 6(18.18 \%), 0(0.00 \%)$ and $1(3.03 \%)$ children, respectively.

Thus, colics were observed in 32 children in the beginning of the study and remained in 19 children by study day 14; however, colics occurred extremely rarely in $12(36.3 \%)$ children, frequently - only in 1 child (pic. 2).

We also analyzed the possibility to resume breast feeding. In the beginning of the study, $10(30.30 \%)$ neonates refused breast; short sucking and anxiety were observed in $3(9.09 \%)$ children; there also were $6(18.18 \%)$ patients who would suck ca. $20-30 \%$ of the required amount and refuse further feeding, $3(9.09 \%)$ patients who would suck ca. $50-60 \%$ of the required amount and refuse further feeding and $11(33.33 \%)$ patients who would easily suck the required amount of breast milk during feeding. The following results were observed after 14 days: $0(0.00 \%), 4(12.12 \%), 3(9.09 \%), 10(30.30 \%)$ and $16(48.48 \%)$, respectively (pic. 3$)$.

Thus, there were $10(30.30 \%)$ children refusing breast in the beginning of the study and non by day 14; there were $14(42.42 \%)$ children who would suck up to $60 \%$ of the required amount or the total amount in the beginning of the study and $26(78.78 \%)$ by the end of the study, i.e. the share of children receiving primarily breast feeding almost doubled. 


\section{CONCLUSION}

Thus, we formulated the following recommendations on support and increase in the spread of breast feeding among children with perinatal pathologies, including premature infants:

- improvement of information awareness and knowledge of the medical personnel regarding issues of breast feeding (lectures, seminars, requalification program); introduction of a new position for a specialist in breast feeding for organizing lectures, seminars, group workshops and domiciliary fostering;

- social propaganda and agitation, advertising in mass media, cultivation of positive image of maternity and breast feeding, maintenance of physical and mental health of the mother and the child by employers, establishment of specialized rooms for breast milk expression at workplaces for working mothers taking into consideration public health standards;

- special medical devices (feeding bottles, pacifiers) Pigeon Peristaltic Plus designed on the basis of the information on neonatal sucking physiology and to reproduce peristaltic component of natural breast sucking are recommended to the involuntarily weaned children. Our studies have demonstrated that use of such bottles with pacifiers considerably decreases aerophagia and colics, helps to teach neonates physiological sucking and gives a real opportunity to resume breast feeding.

\section{REFERENCES}

1. Agostoni C., Braegger Ch., Decsi T., Kolacek S., Koletzko B., Michaelsen K. F., Mihatsch W., Moreno L., Puntis J., Shamir R., Szajewska H., Turck D., van Goudoever J. ESPGHAN Committee on Nutrition. Breast-feeding: A Commentary by the ESPGHAN Committee on Nutrition. Journal of Pediatric Gastroenterology \& Nutrition. 2009; 49 (1): 112-125. Doi: 10.1097/MPG.0b013e31819f1e05.

2. Natsional'naya programma optimizatsii vskarmlivaniya detei pervogo goda zhizni $v$ Rossiiskoi Federatsii. Soyuz pediatrov Rossii, Natsional'naya assotsiatsiya dietologov i nutritsiologov [National Program of Feeding Optimization in Neonates in the Russian Federation. Union of Pediatricians of Russia, National Association of Dietetics and Nutrition]. Moscow, 2010. pp. 34 38.

3. Rukovodstvo po neonatologii. Pod red. zasluzhennogo deyatelya nauki RF, professora $G$. $V$. Yatsyk [Guidelines on Neonatology. Ed. by Honored Scientist of the Russian Federation, Professor G.V. Yatsyk]. Moscow, Gardariki, 2004.

4. Belyaeva I. A. Voprosy sovremennoi pediatrii - Current pediatrics. 2011; 10 (3): 86-92. 5. Groh-Wargo S., Sapsford A. Enteral nutrition support of the preterm infant in the neonatal intensive care unit. Nutrition in Clinical Practice. 2009; 24 (3): 363-376.

6. Morales Y., Schanler R. J. Human milk and clinical outcomes in VLBW infants: how compelling is the evidence of benefit? Seminars in Perinatology. 2007; 31 (2): 83-88.

7. Schanler R. J. Outcomes of human milk-fed premature infants. Seminars in Perinatology. 2011; 35 (1): 29-33.

8. Schurr P., Perkins E. M. The relationship between feeding and necrotizing enterocolitis in very low birth weight infants. Neonatal Network. 2008; 27 (6): 397-407.

9. Agostoni C., Braegger C., Decsi T. et al. ESPGHAN Committee on Nutrition. Breast-feeding:

A Commentary by the ESPGHAN Committee on Nutrition. Journal of Pediatric

Gastroenterology and Nutrition. 2009; 49 (1): 112-125.

10. Sisk P. M., Lovelady C. A., Grube K. J. et al. Human milk consumption and full enteral feeding among infants who weigh $<1250$ grams. Pediatrics. 2008; 121 (6): 1528-1533.

11. Horwood L. J., Darlow B. A., Mogridge N. Breast milk feeding and cognitive ability at 7-8 years. Archives of Disease in Childhood. Fetal and Neonatal Edition. 2001; 84 (1): 23-27. 
12. Lucas A., Morley R., Cole T. J. et al. A randomized multicentre study on human milk versus formula and later development in preterm infants. Archives of Disease in Childhood. Fetal and Neonatal Edition. 1994; 70: 141-146.

13. Lucas A., Morley R., Cole T. J. et al. Early diet in preterm babies and developmental status in 18 months. Lancet. 1990; 335 (8704): 1477-1481.

14. Mortensen E. L., Michaelsen K. F., Sanders S. A. et al. The association between duration of breastfeeding and adult intelligence. Journal of the American Medical Association. 2002; 287 (18): 2365-2371.

15. Vohr B. R., Poindexter D. D., Dusick A. M. et al. Beneficial effects of breast milk in the neonatal intensive care unit on the developmental outcome of extremely low birth weight infants at 18 months of age. Pediatrics. 2006; 118 (1): 115-123.

16. Baranov A.A., Namazova-Baranova L.S., Belyaeva I.A., Skvortsova V.A., Turti T.V., Tarzyan E.O. Vestnik Rossiiskoi akademii meditsinskikh nauk - Annals of the Russian Academy of Medical Sciences. 2013; 4: 10-16.

17. Printsipy etapnogo vykhazhivaniya nedonoshennykh detei. Pod red. chl.-korr. RAMN, prof. L.S. Namazovoi-Baranovoi [Principles of Step-wise Nursing of Premature Infants. Edited by corr. memb. of RAMS L.S. Namazova-Baranova]. Moscow, Pediatr"", 2013.

Pic. 1. Aerophagia rate in the beginning of the study, after 7 and 14 days

Pic. 2. Rate of colics in the beginning of the study, after 7 and 14 days

Pic. 3. Potential for resuming breast feeding

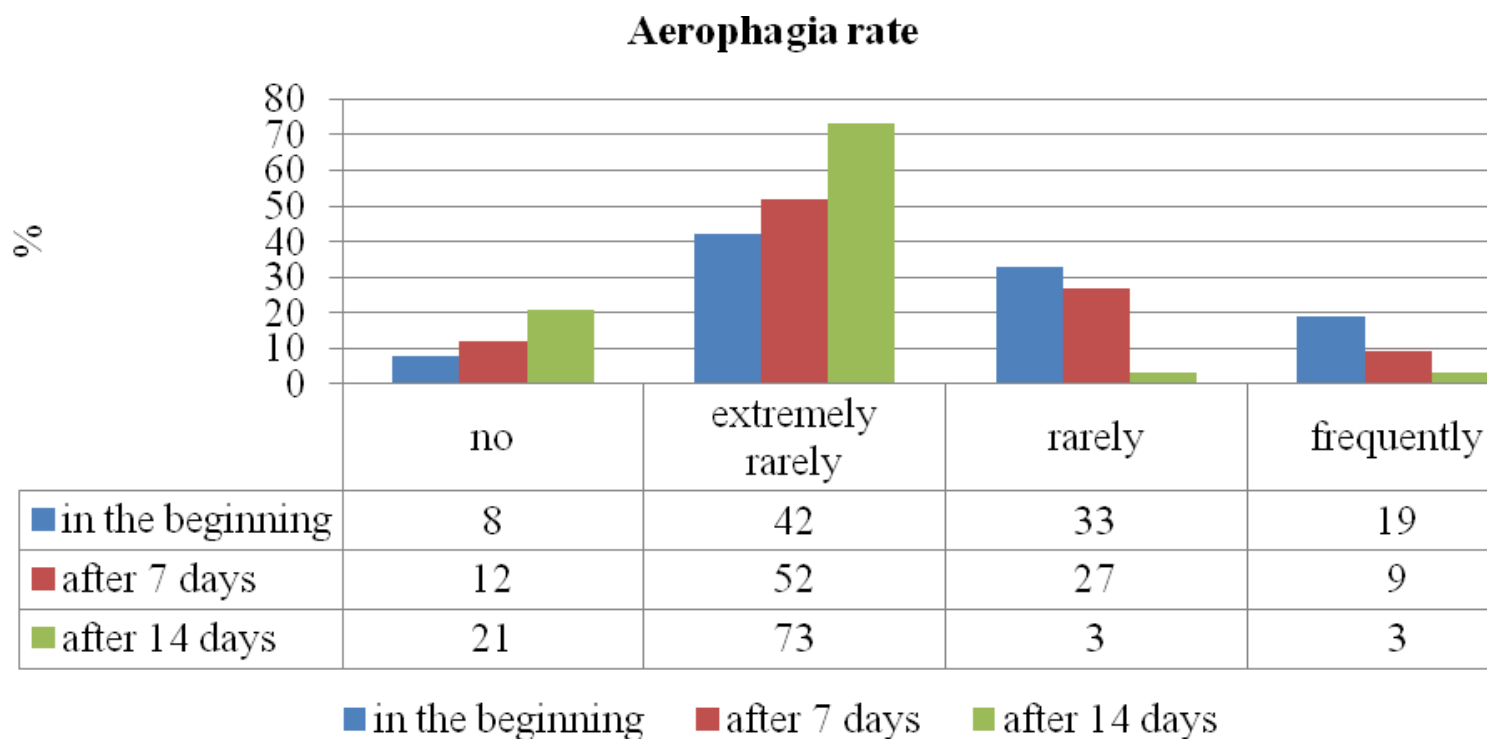



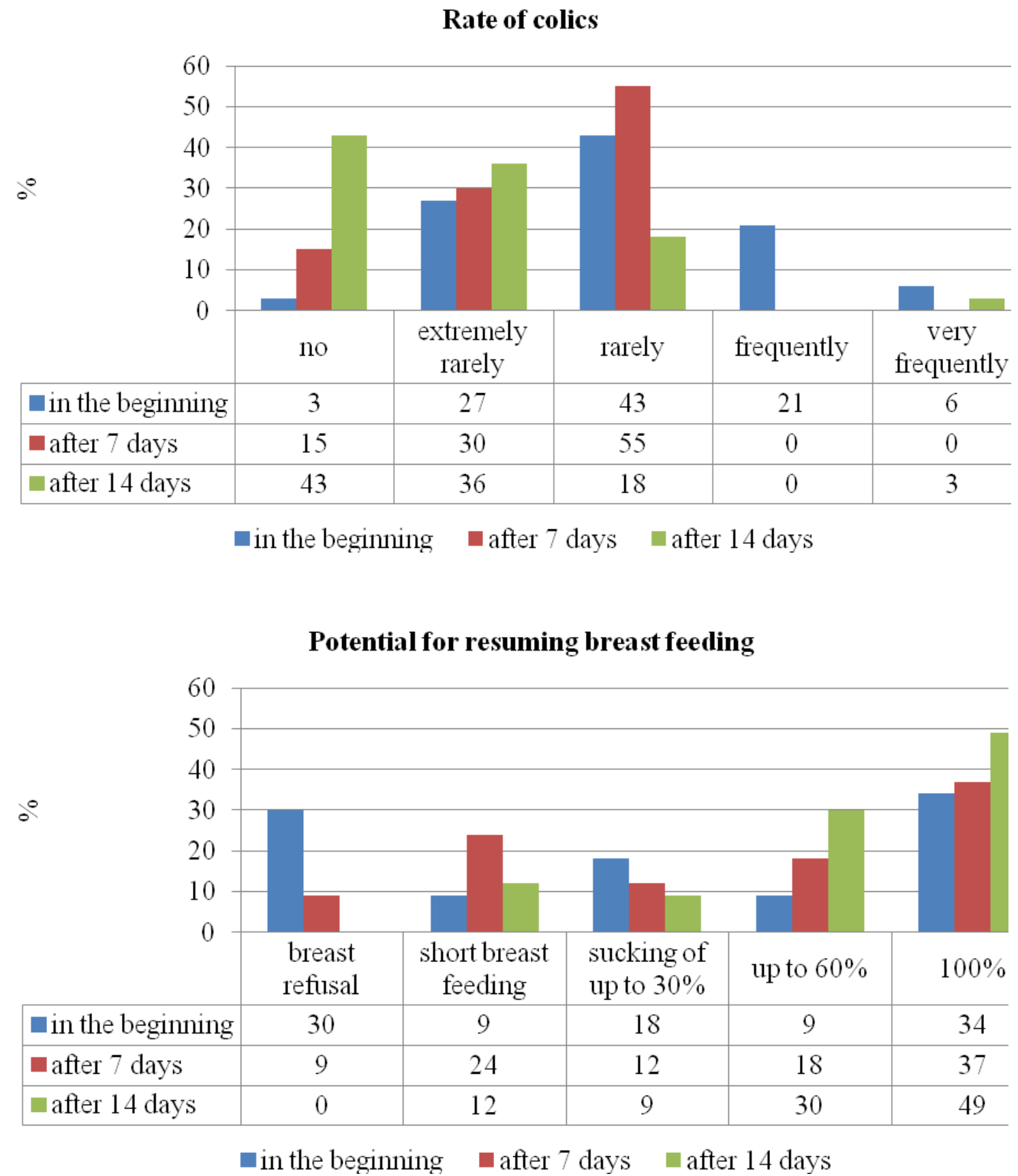